\title{
Autonomous trisomic rescue of Down syndrome cells
}

\author{
Momoko Inoue ${ }^{1,2} \cdot$ Kazuhiro Kajiwara $^{1,2} \cdot$ Ayumi Yamaguchi ${ }^{1} \cdot{\text { Tohru Kiyono } \mathbb{1}^{3} \cdot \text { Osamu Samura }}^{2} \cdot$ \\ Hidenori Akutsu ${ }^{1} \cdot$ Haruhiko Sago $^{4} \cdot$ Aikou Okamoto $^{2} \cdot$ Akihiro Umezawa $^{1}$
}

Received: 3 October 2018 / Revised: 4 January 2019 / Accepted: 15 January 2019 / Published online: 13 February 2019

(c) The Author(s) 2019. This article is published with open access

\begin{abstract}
Down syndrome is the most frequent chromosomal abnormality among live-born infants. All Down syndrome patients have mental retardation and are prone to develop early onset Alzheimer's disease. However, it has not yet been elucidated whether there is a correlation between the phenotype of Down syndrome and the extra chromosome 21 . In this study, we continuously cultivated induced pluripotent stem cells (iPSCs) with chromosome 21 trisomy for more than 70 weeks, and serendipitously obtained revertant cells with normal chromosome 21 diploids from the trisomic cells during long-term cultivation. Repeated experiments revealed that this trisomy rescue was not due to mosaicism of chromosome 21 diploid cells and occurred at an extremely high frequency. We herewith report the spontaneous correction from chromosome 21 trisomy to disomy without genetic manipulation, chemical treatment or exposure to irradiation. The revertant diploid cells will possibly serve a reference for drug screening and a raw material of regenerative medicinal products for cell-based therapy.
\end{abstract}

\section{Introduction}

Recently, attention to prenatal diagnosis is increasing due to the higher average age of pregnant women. Due to the availability of diagnostic techniques such as non-invasive prenatal genetic testing and improvement of imaging technology, congenital diseases including chromosomal abnormalities are possible to diagnose earlier than before $[1,2]$. On the other hand, there are few genetic disorders in which early diagnosis contributes to the improvement of the prognosis of children. Down syndrome is the most frequent chromosomal abnormality among live-born infants. All Down syndrome patients have mental retardation and are prone to develop early

Akihiro Umezawa

umezawa@1985.jukuin.keio.ac.jp

1 Department of Reproductive Biology, National Center for Child Health and Development, Tokyo 157-8535, Japan

2 Department of Obstetrics and Gynecology, The Jikei University School of Medicine, Tokyo 105-8471, Japan

3 Division of Carcinogenesis and Cancer Prevention, Department of Cell Culture Technology, National Cancer Center Research Institute, Tokyo 104-0045, Japan

4 Department of Maternal-Fetal, Neonatal and Reproductive Medicine, National Center for Child Health and Development, Tokyo 157-8535, Japan onset Alzheimer's disease. In addition, leukemia, cardiac malformation, hearing disorders, and vision disorders are also seen at a high rate. Hyperkeratosis of the skin is occasionally observed [3]. Ninety percent of Down syndrome cases are due to an extra copy of chromosome 21 and the remainder exhibit imbalanced translocation or mosaicism. Triplication of specific regions of chromosome 21, band 21q22, causes various physical and cognitive phenotypes of Down syndrome, and the causative genes include amyloid beta precursor protein (APP) related to Alzheimer's disease, and superoxide dismutase 1 (SOD 1) involved in the onset of amyotrophic lateral sclerosis [4, 5]. In addition, dual specificity tyrosine phosphorylation-regulated kinase 1A (DYRK1A) and Down syndrome critical region gene 1 (DSCR1) on chromosome 21 are related to neurogenesis [6]. DYRK1A has attracted attention as a target for normalizing the phenotype of Down syndrome [7, 8]. DYRK1A inhibitor as a therapeutic agent for Down syndrome has been widely studied and developed and has been tested in clinical trials [9]. Additionally, low molecular weight molecules that improve the phenotype of Down syndrome have also been tested [10].

To develop drugs for Down syndrome, murine models for Down syndrome or trisomy 21 have been developed. Since the distal part of mouse chromosome 16 is orthologous to a large portion of human chromosome 21 , mouse models, in particular the chromosome 16 segmental trisomies, Ts65Dn and Ts1Cje, were produced $[11,12]$. These 
models are used for exploration of the etiology of Down syndrome and drug development [13-15]. Ts65Dn mice mimic the human condition, including developmental delay [16] and memory deficit, and may therefore be used for drug development with the aim of improving cognitive function [7]. Likewise, Ts1Cje carries a segmental trisomy of mouse chromosome 16 [12] and shows Down syndromerelated abnormalities such as craniofacial alterations [17] and spatial learning deficits [12]. Maternal supplementation of low molecular weight molecules such as epigallocatechin-3-gallate, fluoxetine, neuroprotective peptide, and choline during pregnancy improve function of these model mice $[8,10,18,19]$. Neural stem cell-based therapy was also attempted with neonatal Down syndrome mice [20]. Further studies are necessary in order to determine the efficacy of these therapies.

Immortality of induced pluripotent stem cells (iPSCs) makes it possible to obtain a large number of cells from a small specimen, and pluripotency enables differentiation into various cell types [21-24]. Therefore, they are widely used to clarify disease etiology and test therapeutic drugs [25-28]. Attempts to normalize chromosomal abnormalities have been drawing intense research interest in the study of Down syndrome using iPSCs. In order to determine the mechanism of development of Down syndrome, normal cells are needed as controls. In a previous study, a comparison between monozygotic twins discordant for trisomy 21 had been performed [29]. Previous studies have reported normalization with using genome editing techniques and spontaneous correction during reprogramming to iPSCs [30-33]. In this study, iPSCs with the normal karyotype, i.e., chromosome 21-diploid cells, was detected at a high frequency in the process of culturing iPSCs derived from a patient with Down syndrome. In order to investigate the properties of trisomy 21 cells, we have characterized disomic and trisomic subclones that are isogenic with the exception of chromosome 21 .

\section{Materials and methods}

\section{Human cells}

Amniotic fluid was obtained from a fetus with Down syndrome associated with polyhydroamnios. It was collected at 29 weeks of gestation for the purpose of reducing amniotic fluid. Cells were incubated in $4 \mathrm{~mL}$ of Amnio-MAX-II complete medium (Invitrogen, catalog number (\#) 11269016). Cell clusters appeared 6 to 7 days after seeding. Nonadherent cells were discarded and the medium replaced every 2 days. When the culture reached subconfluence, cells were harvested with a trypsin-EDTA solution (Wako, \#209-16941) and re-plated at a 1:8 ratio in a $60-\mathrm{mm}$ dish.

\section{Cell culture}

Amniotic fluid-cells and iPSCs were cultured as described in previous literature [34-37]. iPSCs were maintained in E8 medium on VTN-coated dishes and passaged using $0.5 \mathrm{mM}$ EDTA in PBS.

\section{Sub-cloning of iPSCs}

Single cells were picked from colonies of iPSCs and cells were seeded at 1 cell/well in a 4-well plate coated with imatrix-511 (nippi, \#892 012). Cells were cultured in StemFit AK02N (ReproCELL, \#RCAK02N) supplemented with $10 \mu \mathrm{M}$ Y-27632 (Wako, \#251-00514) and those which showed colony formation were passaged.

\section{Real-time qPCR}

RNA was extracted from cells using the RNeasy Mini kit (Qiagen, \#74104). An aliquot of total RNA was reversetranscribed using an oligo (dT) primer (Invitrogen, \#18418020). For the thermal cycle reactions, the cDNA template was amplified (Applied Biosystems Quantstudio 12 K Flex RealTime PCR System) with gene-specific primer sets (Table 1) using the Platinum SYBR Green qPCR SuperMix-UDG with

Table 1 List of primers for qRT-PCR

\begin{tabular}{lll}
\hline Gene & Primer sequence & \\
\hline DYRK1A & Forward & CTGGACTCTTCCCTCCCTTC \\
& Reverse & GCCGAACAGATGAAGGTTTG \\
APP & Forward & TTTGGCACTGCTCCTGCT \\
& Reverse & CCACAGAACATGGCAATCTG \\
SOD1 & Forward & CTAGCGAGTTATGGCGACG \\
& Reverse & CCACACCTTCACTGGTCCAT \\
ETS2 & Forward & GCCTCCCTGATCGTCTCTG \\
& Reverse & TGGTCCATATTCTTGATTCCG \\
DSCR1 & Forward & AGTGGGATGGAAACAAGTGG \\
& Reverse & GCTGCGTGCAATTCATACTT \\
GAPDH & Forward & TGTTGCCATCAATGACCCCTT \\
& Reverse & CTCCACGACGTACTCAGCG \\
KRT14 & Forward & GACCATTGAGGACCTGAGGA \\
& Reverse & CATACTTGGTGCGGAAGTCA \\
p63 & Forward & GAAGATCCCATCACAGGAAGAC \\
& Reverse & GTTTCAATTGTGTGCTGAGGAA \\
TERT & Forward & GAGCAAGTTGCAAAGCATTG \\
& Reverse & TTTCTCTGCGGAAGGTTCTG \\
cycliD1 & Forward & TGCTGCTGGAAATGCTGACT \\
& Reverse & TTTGTACAAGAAAGCTGGT \\
CDK4R24C & Forward & TGCTGCTGGAAATGCTGACT \\
& Reverse & TTTGTACAAGAAAGCTGGGT \\
\hline
\end{tabular}


ROX (Invitrogen, \#11733-046) under the following reaction conditions: 40 cycles of PCR $\left(95^{\circ} \mathrm{C}\right.$ for $15 \mathrm{~s}$ and $60^{\circ} \mathrm{C}$ for 1 min) after an initial denaturation $\left(95^{\circ} \mathrm{C}\right.$ for $\left.2 \mathrm{~min}\right)$. Fluorescence was monitored during every PCR cycle at the annealing step. mRNA levels were normalized using glyceraldehyde-3phosphate dehydrogenase as a housekeeping gene.

\section{Immunocytochemical analysis}

Cells were fixed with $4 \%$ paraformaldehyde (PFA) in PBS for $10 \mathrm{~min}$ at $4{ }^{\circ} \mathrm{C}$. After washing with PBS and treatment with $0.1 \%$ Triton X-100 (Sigma-Aldrich, \#T8787-100 $\mathrm{ML}$ ) for $10 \mathrm{~min}$ at $4{ }^{\circ} \mathrm{C}$, the cells were incubated with $5 \%$ normal goat serum (Dako, \#X 0907) in PBS for $30 \mathrm{~min}$ Pre-incubated at room temperature. Followed by reaction with primary antibody in blocking buffer for $24 \mathrm{~h}$ at $4{ }^{\circ} \mathrm{C}$. After washing with PBS, the cells were incubated with fluorescently conjugated secondary antibody. Anti-rabbit or anti-mouse immunoglobulin $\mathrm{G}$ ( $\mathrm{IgG}$ ) bound to Alexa 488 or 546 (1:1000) was incubated in blocking buffer for $30 \mathrm{~min}$ at room temperature. The nuclei were stained with DAPI (Biotium, \#40043). All images were captured using confocal microscopy (Confocal microscope C2+). Antibody information is provided in the Table 2 .

\section{Fluorescent in situ hybridization (FISH)}

FISH analysis was performed using the ZytoLight FISHCytology Implementation Kit (Zytovision, \#Z-2099-20). Potassium chloride solution $0.075 \mathrm{M}$ was added to the trypsin-treated cell suspension and allowed to stand for 20 min, and then fixed with Carnoy solution. The Carnoy fixative was dripped onto the coverslip and air dried. Coverslips were immersed in $2 \times \mathrm{SSC}$ at $37^{\circ} \mathrm{C}$ for $30 \mathrm{~min}$. Cells were dehydrated in 70, 90, 100\% ethanol for $2 \mathrm{~m}$ and air dried. Proteolysis and washing were then performed using the ZytoLight FISH-Cytology Implementation Kit according to the manufacturer's protocol, followed by dehydration with 70, 90, and $100 \%$ ethanol for 1 min each, followed by air drying. After labeling the SPEC 21q22 probe (Zytolight, \#Z-2086) according to the manufacturer's protocol, the cells and probes were denatured on a hotplate at $72{ }^{\circ} \mathrm{C}$ for $2 \mathrm{~min}$ and hybridized overnight in a humidity chamber at $37^{\circ} \mathrm{C}$. Cells were then washed and mounted.

\section{Karyotypic analysis}

Karyotypic analysis was performed at the Chromosome Science Labo Inc. Chromosome spreads were Giemsa
Table 2 List of antibodies for immunochemistry

\begin{tabular}{|c|c|c|c|}
\hline & Class & Company & Dilution \\
\hline \multicolumn{4}{|l|}{ Primary antibodies } \\
\hline Anti-PAX6 antibody & Rabbit IgG & abcam & $1 / 350$ \\
\hline Anti-Nestin antibody & Mouse IgG1 & abcam & $1 / 350$ \\
\hline Keratin 14 polyclonal antibody & Rabbit polyclonal & BioLegend & $1 / 1000$ \\
\hline Anti-P63 (4A4) antibody & Mouse IgG2a & abcam & $1 / 50$ \\
\hline Monoclonal Anti-Involucrin antibody produced in mouse & Mouse IgG & Sigma-Aldrich & $1 / 200$ \\
\hline Anti laminin 5 antibody & Rabbit polyclonal & abcam & $1 / 200$ \\
\hline Loricrin polyclonal antibody & Rabbit polyclonal & BioLegend Inc & $1 / 1000$ \\
\hline Keratin 15 polyclonal antibody & Rabbit polyclonal & BioLegend Inc & $1 / 1000$ \\
\hline Anti-Ki67 antibody & Rabbit polyclonal & abcam & $1 / 100$ \\
\hline Anti-Pan-cytokeratin antibody & Mouse IgG1 & eBioscience & $1 / 200$ \\
\hline \multicolumn{4}{|l|}{ Secondary antibodies } \\
\hline $\begin{array}{l}\text { Goat anti-rabbit IgG }(\mathrm{H}+\mathrm{L}) \text { Secondary antibody, Alexa } \\
\text { Fluor } 546\end{array}$ & None & Invitrogen & $1 / 1000$ \\
\hline $\begin{array}{l}\text { Goat anti-Mouse IgG1 Secondary antibody, Alexa Fluor } \\
488\end{array}$ & None & Invitrogen & $1 / 1000$ \\
\hline $\begin{array}{l}\text { Goat anti-Mouse IgG3 Secondary antibody, Alexa Fluor } \\
488\end{array}$ & None & Invitrogen & $1 / 1000$ \\
\hline $\begin{array}{l}\text { Goat anti-Mouse IgG2a Secondary Antibody, Alexa Fluor } \\
488\end{array}$ & None & Invitrogen & $1 / 1000$ \\
\hline $\begin{array}{l}\text { Goat anti-Mouse IgG1 Secondary Antibody, Alexa Fluor } \\
546\end{array}$ & None & Invitrogen & $1 / 1000$ \\
\hline $\begin{array}{l}\text { rabbit anti-Mouse } \operatorname{IgG}(\mathrm{H}+\mathrm{L}) \text { Secondary Antibody, Alexa } \\
\text { Fluor } 488\end{array}$ & None & Invitrogen & $1 / 1000$ \\
\hline $\begin{array}{l}\text { Goat anti-rabbit IgG }(\mathrm{H}+\mathrm{L}) \text { Secondary antibody, Alexa } \\
\text { Fluor } 488\end{array}$ & None & Invitrogen & $1 / 1000$ \\
\hline
\end{tabular}


banded and photographed. Twenty metaphase spreads were analyzed for each sample and karyotyped using a chromosome imaging analyzer system (Applied Spectral Imaging).

\section{Short tandem repeat analysis}

STR analysis was conducted at BEX facility. Genomic DNA was used and 16 microsatellite markers were amplified by PCR using microsatellite specific primers.

\section{Growth curve}

Trisomic or disomic iPSCs $\left(1 \times 10^{5}\right.$ per well $)$ were seeded in a 6-well plate coated with imatrix-511 (nippi, \#892 012). The total number of cells/well was counted 2, 4, and 6 days after plating.

\section{Microarray analysis}

RNA extraction and microarray analysis were performed at DNA Chip Research Inc. RNA extraction was performed using the Qiagen RNeasy mini kit (Qiagen, \#74104) and cRNA synthesis was carried out according to the manufacturer's protocol using Low Input Quick Amp Labeling Kit (Agilent, \#5190-2305). Hybridization was performed using SurePrint G3 Human Gene Expression $8 \times 60 \mathrm{~K}$ v3 (Agilent, G4858A \#072363).

\section{Fluorescence-activated cell sorting analysis}

The expression of cell-surface markers was analyzed by BD LSR Fortessa (BD Biosciences). Primary antibodies were incubated for $1 \mathrm{~h}$ in PBS with $1 \%$ BSA. After washing with PBS, cells were incubated with fluorescently coupled secondary antibodies; anti-rabbit $\mathrm{IgG}$ conjugated with Alexa 488 (1:1000) for $30 \mathrm{~min}$ at room temperature.

\section{Differentiation of iPSCs into neural stem cells (NSCs)}

Differentiation of iPSCs into NSCs was accomplished using Neurobasal medium (Gibco, \#21103049) according to the protocol. We subcultured iPSCs on VTN coated 60$\mathrm{mm}$ dish in E8 medium on day 1. iPSCs were cultured in Neurobasal medium supplemented with neural induction supplement (Gibco, \#A1647701) for 6 days. On day 7, the cells were passaged to $60-\mathrm{mm}$ dish coated with geltrex (Gibco, \#A1413202) and maintained in mixture of Neurobasal Medium and Advanced DMEM/F12 (Gibco, \#12634010) (1:1) supplemented with neural induction supplement and $5 \mu \mathrm{M} \mathrm{Y-27632.}$

\section{Differentiation of iPSCs into keratinocytes}

The induction of differentiation into keratinocytes was carried out as previously described. We subcultured small clumps of undifferentiated iPSC on VTN coated 10-mm dish in E 8 medium on day 1. iPSCs were then cultured for 4 days in DKSFM (Invitrogen, \#10744-019) supplemented with $1 \mathrm{mM}$ all-trans RA (Wako, \#182-01111) and $10 \mathrm{ng} / \mathrm{mL}$ bone morphogenetic protein 4 (BMP4) (R\&D systems, \#314-BP-010/CF). Subsequently, iPSC was maintained in DKSFM supplemented with $20 \mathrm{ng} / \mathrm{mL}$ EGF (R\&Dsystems, \#236-EG-200) for 10 days, then passaged to a 10-mm dish coated with $0.03 \mathrm{mg} / \mathrm{mL}$ type I collagen and $0.01 \mathrm{mg} / \mathrm{mL}$ fibronectin, and maintained in DKSFM supplemented with $10 \mu \mathrm{M}$ Y-27632 (Wako, \#251-00514) and $20 \mathrm{ng} / \mathrm{mL}$ EGF.

\section{Viral vector construction and viral transduction}

Construction of the lentiviral vector plasmids CSII-CMVTet-Off, CSII-TRE-Tight-cyclin D1, and CSII-TRE-TightCDK4R24C was previously described [38]. In brief, the EF1a promoter in CSII-EF-RfA (a gift from Dr. H. Miyoshi, RIKEN) was replaced with a tetracycline-inducible promoter, TRE-Tight, from pTRE-Tight (Clontech, \#631059) to generate CSII-TRE-Tight-RfA. Human cyclin D1, human mutant CDK4 (CDK4R24C: an INK4a-resistant form of CDK4), and hTERT were inserted into the entry vector via a BP reaction (Invitrogen, Carlsbad, CA). These segments were then recombined with CSII-TRE-Tight-RfA through an LR reaction (Invitrogen) to generate CSII-TRE-Tightcyclin D1, CSII-TRE-Tight-CDK4R24C, and CSII-TRETight-hTERT. The rtTA segment from pTet-Off Advanced (Clontech) was amplified by PCR, recombined with the donor vector pDONR221 via a BP reaction (Invitrogen) to generate pENTR221-Tet-Off, and then recombined with a lentiviral vector, CSII-CMV-RfA, through an LR reaction (Invitrogen) to generate CSII-CMV-Tet-Off. Recombinant lentiviruses with vesicular stomatitis virus $\mathrm{G}$ glycoprotein were produced as described previously [39]. Keratinocytes were inoculated with $5 \times 10^{6}$ infectious units [IU] each of CSII-CMV-hTERT, CSII-CMV-Tet-Off, CSII-TRE-Tightcyclin D1 and CSII-TRE-Tight-CDK4R24C lentiviruses in the presence of $4 \mu \mathrm{g} / \mathrm{mL}$ of polybrene.

\section{Results}

\section{Reversion of chromosome 21 trisomy to disomy}

We established five independent iPSC lines (\#1, \#5, \#6, \#9, and \#12) from amniotic fluid-derived cells from patients with Down syndrome. Karyotypic analysis revealed that 
the all iPSC \#1, \#5, \#6, \#9, and \#12 exhibited chromosome 21 trisomy $(47, \mathrm{XX},+21)$ in $100 \%$ of the lines (20 out of 20 metaphase cells) (Fig. 1a-e). We have been cultivating the iPSCs for more than 70 weeks (each passage was performed every 4-5 days). We have continuously investigated karyotypes of the iPSCs and observed normal
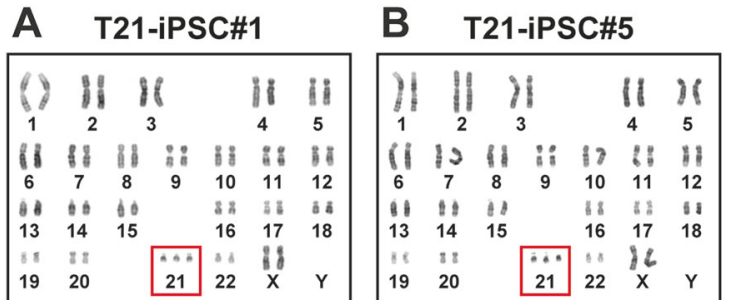

\section{E T21-iPSC\#12}

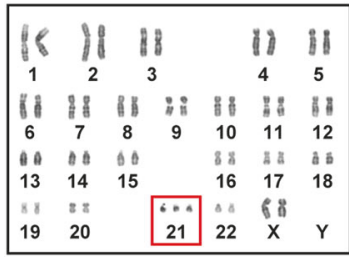

\section{F D21-iPSC\#1}

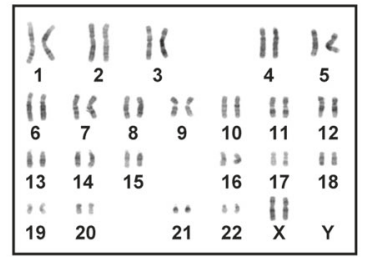

\section{T21-iPSC\#6}

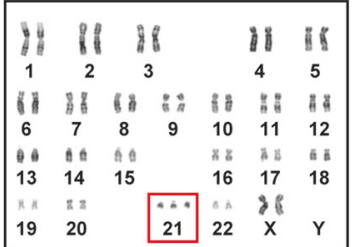

\section{G D21-iPSC\#2}

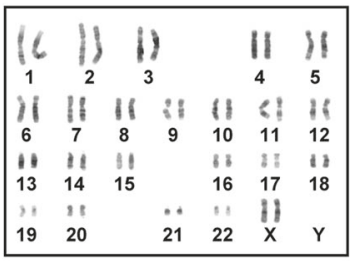

\section{H}

T21-iPSC\#12
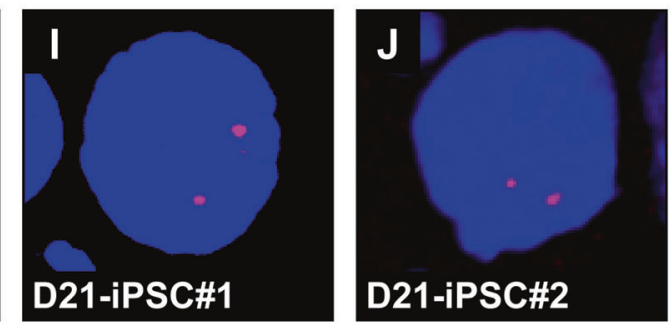

\section{K}

\begin{tabular}{|c|c|c|c|c|c|c|c|}
\hline Locus & \multicolumn{3}{|c|}{ T21-iPSC\#12 } & \multicolumn{2}{|c|}{ D21-iPSC\#1 } & \multicolumn{2}{|c|}{ D21-iPSC\#2 } \\
\hline D3S1358 & 15 & 16 & & 15 & 16 & 15 & 16 \\
\hline TH01 & 6 & 7 & & 6 & 7 & 6 & 7 \\
\hline D21S11 & 30 & 31 & 32 & 31 & 32 & 31 & 32 \\
\hline D18S51 & 13 & 15 & & 13 & 15 & 13 & 15 \\
\hline Penta_E & 12 & 19 & & 12 & 19 & 12 & 19 \\
\hline D5S818 & 12 & & & 12 & & 12 & \\
\hline D13S317 & 11 & 12 & & 11 & 12 & 11 & 12 \\
\hline D7S820 & 10 & 12 & & 10 & 12 & 10 & 12 \\
\hline D16S539 & 9 & 11 & & 9 & 11 & 9 & 11 \\
\hline CSF1PO & 10 & & & 10 & & 10 & \\
\hline Penta_D & 9 & 10 & 11 & 9 & 11 & 9 & 11 \\
\hline \multicolumn{8}{|l|}{ AMEL } \\
\hline vWA & 14 & 19 & & 14 & 19 & 14 & 19 \\
\hline D8S1179 & 12 & 13 & & 12 & 13 & 12 & 13 \\
\hline TPOX & 10 & 12 & & 10 & 12 & 10 & 12 \\
\hline FGA & 22 & & & 22 & & 22 & \\
\hline
\end{tabular}

Fig. 1 Trisomy rescue. a Karyotypic analysis in T21-iPSC \#1. All of the cells ( 20 out of 20 cells) had typical trisomy karyotypes $(47, \mathrm{XX},+21)$. b Karyotypic analysis in T21-iPSC \#5. All of the cells (20 out of 20 cells) had typical trisomy karyotypes $(47, \mathrm{XX},+21)$. c Karyotypic analysis in T21-iPSC \#6. All of the cells ( 20 out of 20 cells) had typical trisomy karyotypes $(47, \mathrm{XX},+21)$. d Karyotypic analysis in T21-iPSC $\# 9$. All of the cells ( 20 out of 20 cells) had typical trisomy karyotypes (47, XX, +21). e Karyotypic analysis in T21-iPSC \#12. All of the cells (20 out of 20 cells) had typical trisomy karyotypes $(47, \mathrm{XX},+21)$.
This panel is duplicated from the reference 34. f Karyotypic analysis in D21-iPSC\#1. D21-iPSC\#1 had normal karyotypes (46, XX). g Karyotypic analysis in D21-iPSC\#2. D21-iPSC\#2 had normal karyotypes (46, XX). h FISH analysis in T21-iPSC\#12 that was trisomic for chromosome 21. i FISH analysis in D21-iPSC\#1 that was disomic for chromosome 21. j FISH analysis in D21-iPSC\#2 that was disomic for chromosome 21. k STR analysis of T21-iPSC\#12, D21-iPSC\#1 and D21-iPSC\#2 
chromosome 21 diploids $(46, \mathrm{XX})$ in four out of 20 cells at passage 70 (corresponding to more than 200 population doublings). We subcloned two lines that were normal diploids from iPSC\#12 with the single-cell dilution method (Fig. 1f, g). FISH analysis confirmed that the clones with chromosome 21 trisomy and disomy in the karyotypic analysis were indeed trisomic and disomic, respectively, for chromosome 21 (Fig. 1h-j). Trisomy 21 iPSCs and normal diploid iPSCs were designated as T21-iPSC\#12 and D21-iPSC\#2, respectively.

STR analysis was performed on these two D21-iPSC clones and T21-iPSC\#12 to eliminate a possibility of contamination with other iPSCs (Fig. 1k). T21-iPSC\#12 had three polymorphisms at two loci (D21S11 and Penta_D) on chromosome 21. In contrast, two D21-iPSC clones lost one repeat polymorphism in the two loci. Loss of the polymorphic pattern in D21S11 and Penta_D was the same in D21-iPSC\#1 and D21-iPSC\#2. The other STR patterns showed the same in T21-iPSC\#12, D21-iPSC\#1, and D21-iPSC\#2, indicating that D21-iPSCs originate from T21-iPSCs.

\section{Comparison of T21-iPSCs and D21-iPSCs}

We examined T21-iPSC\#12 and D21-iPSC\#2 to investigate difference of the growth rate. The growth rates of these two clones were comparable (Fig. 2a). We performed gene chip analysis on T21-iPSC\#12, D21-iPSC\#1, and D21-iPSC\#2 to investigate gene expression levels. Expression levels of genes on chromosome 21 and all chromosomes are shown in heat map and hierarchical clustering analysis (Fig. 2b, c). D21-iPSC\#1 and -2, i.e., two independent iPSC subclones with normal chromosome 21 , are categorized into the same group. Up-regulated and down-regulated genes at 10-fold difference are listed in Tables 3 and 4. We then performed qRT-PCR analysis of the genes on Chromosome 21, based on the results of the gene chip analysis (Fig. 2d-h). The expression levels of the genes for APP (Alzheimer's disease marker), DYRK1A, DSCR1 (Down-syndrome critical region 1), ETS2 and SOD1, all of which are located in chromosome 21, decreased to two-thirds in D21-iPSC\#2, compared to T21-iPSC\#12, implying that the revertant cells regained the gene expression levels of intact iPSCs.
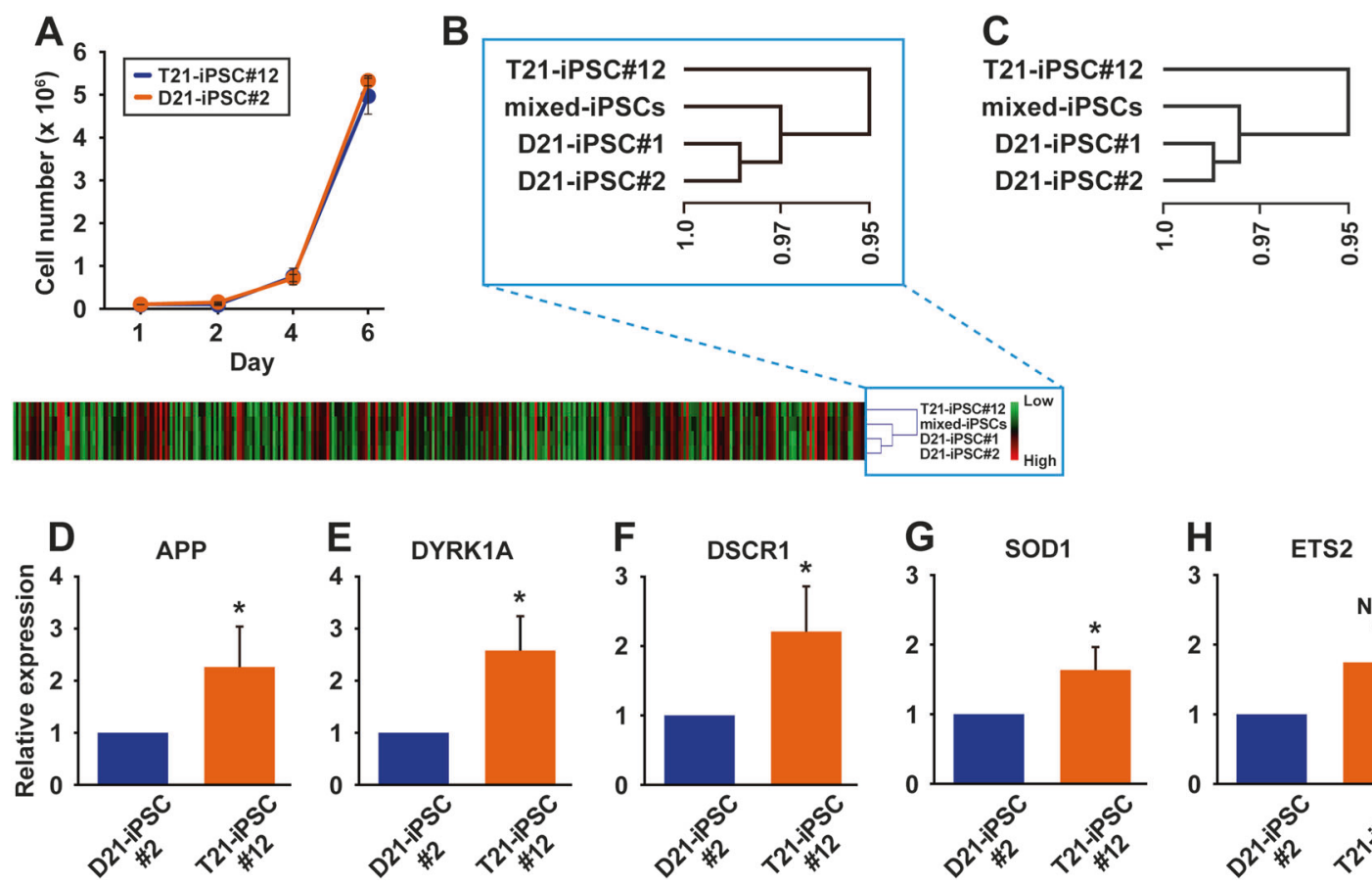
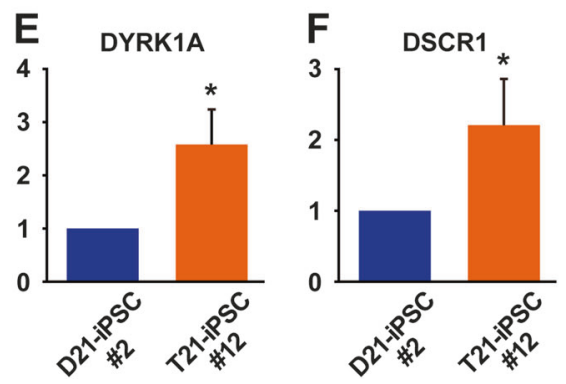
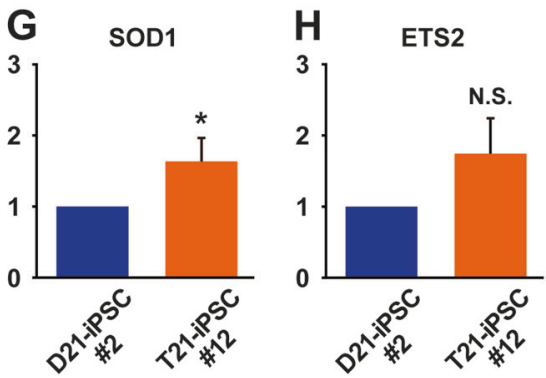

Fig. 2 Comparison of trisomic and disomic iPS cells. a Growth rate of T21-iPSC\#12 and D21-iPSC\#2. Data shown are mean \pm SD of the cell number from three independent experiments. b Heat map and hierarchical clustering of the normalized gene expression values in T21iPSC\#12, D21-iPSC\#1, D21-iPSC\#2, and mixed-iPSCs for the genes on chromosome 21. Hierarchical clustering of genes using MultiExperiment Viewer. c Hierarchical clustering of the normalized gene expression values in T21-iPSC\#12, D21-iPSC\#1, D21-iPSC\#2, and mixed-iPSCs for all the genes. Hierarchical clustering of genes using Multi-Experiment Viewer. d Quantitative RT-PCR analysis for expression of APP in T21-iPSC\#12 and D21-iPSC\#2. Data shown are mean $\pm \mathrm{SD}$ of the expression from three independent experiments.
$* p<0.05$. e Quantitative RT-PCR analysis for expression of DYRK1A in T21-iPSC\#12 and D21-iPSC\#2. Data shown are mean \pm SD of the expression from three independent experiments. $* p<0.05$. f Quantitative RT-PCR analysis for expression of DSCR1 in T21-iPSC\#12 and D21-iPSC\#2. Data shown are mean \pm SD of the expression from three independent experiments. ${ }^{*} p<0.05$. g Quantitative RT-PCR analysis for expression of SOD1 in T21-iPSC\#12 and D21-iPSC\#2. Data shown are mean $\pm \mathrm{SD}$ of the expression from three independent experiments. $* p<0.05$. h Quantitative RT-PCR analysis for expression of ETS2 in T21-iPSC\#12 and D21-iPSC\#2. Data shown are mean \pm SD of the expression from three independent experiments. N.S., not significant 
Table 3 Up-regulated genes

\begin{tabular}{|c|c|c|c|c|c|c|}
\hline Gene symbol & T21-iPSCs & D21-iPSCs-1 & D21-iPSCs-2 & Chromosome number & $\begin{array}{l}\text { T21-iPSCs/ } \\
\text { D21-iPSCs-1 }\end{array}$ & $\begin{array}{l}\text { T21-iPSCs/ } \\
\text { D21-iPSCs-2 }\end{array}$ \\
\hline LEFTY1 & 358 & 19 & 24 & chr1 & 19 & 15 \\
\hline FOXD3 & 493 & 46 & 151 & chr1 & 11 & 3 \\
\hline RGS5 & 1177 & 59 & 194 & chr1 & 20 & 6 \\
\hline lnc-ITGB3BP-1 & 1279 & 123 & 345 & chr1 & 10 & 4 \\
\hline EPAS1 & 162 & 12 & 12 & $\operatorname{chr} 2$ & 14 & 13 \\
\hline TTN & 296 & 20 & 48 & $\operatorname{chr} 2$ & 15 & 6 \\
\hline RAB17 & 2194 & 171 & 400 & $\operatorname{chr} 2$ & 13 & 5 \\
\hline MME & 151 & 15 & 45 & chr3 & 10 & 3 \\
\hline TNIK & 175 & 15 & 58 & $\operatorname{chr} 3$ & 11 & 3 \\
\hline FLJ46120 & 286 & 21 & 59 & $\operatorname{chr} 3$ & 14 & 5 \\
\hline KLKB1 & 190 & 17 & 48 & $\operatorname{chr} 4$ & 11 & 4 \\
\hline AFP & 387 & 32 & 55 & $\operatorname{chr} 4$ & 12 & 7 \\
\hline SLC39A8 & 1067 & 97 & 151 & $\operatorname{chr} 4$ & 11 & 7 \\
\hline CXCL14 & 384 & 25 & 43 & $\operatorname{chr} 5$ & 15 & 9 \\
\hline lnc-MYO6-2 & 117 & 9 & 30 & chr6 & 13 & 4 \\
\hline TRDN & 1022 & 37 & 33 & chr6 & 27 & 31 \\
\hline lnc-MACC1-1 & 110 & 13 & 9 & chr7 & 9 & 13 \\
\hline lnc-MACC1-1 & 498 & 13 & 14 & $\operatorname{chr} 7$ & 37 & 36 \\
\hline LOC101927668 & 1606 & 17 & 20 & $\operatorname{chr} 7$ & 95 & 79 \\
\hline LOC101927668 & 1613 & 17 & 22 & $\operatorname{chr} 7$ & 96 & 72 \\
\hline \multirow[t]{3}{*}{ LOC101927668 } & 1705 & 17 & 25 & chr7 & 99 & 68 \\
\hline & 540 & 16 & 31 & chr8 & 34 & 18 \\
\hline & 1204 & 38 & 45 & chr8 & 32 & 27 \\
\hline ANXA1 & 193 & 22 & 19 & chr9 & 9 & 10 \\
\hline XLOC_12_002441 & 258 & 19 & 44 & $\operatorname{chr} 11$ & 14 & 6 \\
\hline LOC100131262 & 465 & 45 & 86 & $\operatorname{chr} 11$ & 10 & 5 \\
\hline GAL & 13527 & 1142 & 1947 & $\operatorname{chr} 11$ & 12 & 7 \\
\hline GDF3 & 241 & 9 & 16 & $\operatorname{chr} 12$ & 27 & 15 \\
\hline METTL7A & 694 & 50 & 87 & $\operatorname{chr} 12$ & 14 & 8 \\
\hline NTS & 704 & 56 & 55 & $\operatorname{chr} 12$ & 13 & 13 \\
\hline LCP1 & 165 & 13 & 17 & $\operatorname{chr} 13$ & 13 & 9 \\
\hline LHFP & 953 & 79 & 173 & $\operatorname{chr} 13$ & 12 & 5 \\
\hline lnc-MDGA2-2 & 1082 & 61 & 60 & chr14 & 18 & 18 \\
\hline ZDHHC22 & 815 & 72 & 122 & $\operatorname{chr} 14$ & 11 & 7 \\
\hline WFDC21P & 122 & 10 & 15 & $\operatorname{chr} 17$ & 12 & 8 \\
\hline MYH2 & 187 & 15 & 17 & $\operatorname{chr} 17$ & 13 & 11 \\
\hline LINC01540 & 99 & 9 & 13 & $\operatorname{chr} 18$ & 11 & 8 \\
\hline VSTM1 & 137 & 9 & 9 & chr19 & 15 & 15 \\
\hline SEMG1 & 313 & 12 & 54 & $\operatorname{chr} 20$ & 25 & 6 \\
\hline \multirow[t]{2}{*}{ B3GALT5-AS1 } & 100 & 9 & 22 & $\operatorname{chr} 21$ & 11 & 5 \\
\hline & 500 & 19 & 38 & $\operatorname{chr} 21$ & 27 & 13 \\
\hline D21S2088E & 2044 & 145 & 468 & $\operatorname{chr} 21$ & 14 & 4 \\
\hline LOC100126447 & 896 & 69 & 132 & $\operatorname{chrX}$ & 13 & 7 \\
\hline
\end{tabular}


Table 4 Down-regulated genes

\begin{tabular}{|c|c|c|c|c|c|c|}
\hline Gene symbol & T21-iPSCs & D21-iPSCs-1 & D21-iPSCs-2 & Chromosome number & $\begin{array}{l}\text { T21-iPSCs/ } \\
\text { D21-iPSCs-1 }\end{array}$ & $\begin{array}{l}\text { T21-iPSCs/ } \\
\text { D21-iPSCs-2 }\end{array}$ \\
\hline TXNIP & 270 & 6137 & 4096 & chr1 & 0.04 & 0.07 \\
\hline G0S2 & 54 & 209 & 1216 & chr1 & 0.26 & 0.04 \\
\hline LOC100130502 & 33 & 2060 & 883 & $\operatorname{chr} 2$ & 0.02 & 0.04 \\
\hline LOC440910 & 13 & 201 & 227 & $\operatorname{chr} 2$ & 0.06 & 0.06 \\
\hline EPHA4 & 188 & 2820 & 1750 & $\operatorname{chr} 2$ & 0.07 & 0.11 \\
\hline \multirow[t]{2}{*}{ LOC100130502 } & 33 & 449 & 291 & $\operatorname{chr} 2$ & 0.07 & 0.11 \\
\hline & 16 & 192 & 105 & $\operatorname{chr} 2$ & 0.08 & 0.15 \\
\hline POTEI & 140 & 1586 & 1610 & $\operatorname{chr} 2$ & 0.09 & 0.09 \\
\hline lnc-SLC4A1AP-1 & 24 & 210 & 494 & $\operatorname{chr} 2$ & 0.11 & 0.05 \\
\hline LIX1 & 10 & 551 & 237 & $\operatorname{chr} 5$ & 0.01 & 0.02 \\
\hline ARRDC3 & 29 & 345 & 305 & $\operatorname{chr} 5$ & 0.03 & 0.07 \\
\hline C6orf141 & 33 & 341 & 248 & chr6 & 0.02 & 0.04 \\
\hline FEZF1-AS1 & 19 & 1341 & 609 & chr7 & 0.04 & 0.08 \\
\hline FEZF1 & 12 & 222 & 112 & chr7 & 0.07 & 0.10 \\
\hline LHX2 & 75 & 2111 & 784 & chr9 & 0.14 & 0.08 \\
\hline LOC440896 & 12 & 143 & 86 & chr9 & 0.02 & 0.05 \\
\hline PAX6 & 9 & 1061 & 488 & $\operatorname{chr} 11$ & 0.03 & 0.09 \\
\hline LMO1 & 53 & 1984 & 731 & $\operatorname{chr} 11$ & 0.04 & 0.09 \\
\hline LHX5-AS1 & 76 & 4092 & 2023 & $\operatorname{chr} 12$ & 0.06 & 0.06 \\
\hline LHX5-AS1 & 12 & 330 & 148 & $\operatorname{chr} 12$ & 0.08 & 0.09 \\
\hline VWF & 38 & 570 & 392 & $\operatorname{chr} 12$ & 0.08 & 0.13 \\
\hline DDIT3 & 26 & 180 & 337 & $\operatorname{chr} 12$ & 0.13 & 0.06 \\
\hline DLK1 & 435 & 21476 & 8833 & chr14 & 0.26 & 0.07 \\
\hline MEG3 & 22 & 711 & 237 & $\operatorname{chr} 14$ & 0.23 & 0.07 \\
\hline DLK1 & 83 & 2319 & 901 & $\operatorname{chr} 14$ & 0.24 & 0.08 \\
\hline POTEB3 & 57 & 1001 & 965 & $\operatorname{chr} 15$ & 0.55 & 0.08 \\
\hline ARRDC4 & 112 & 1416 & 1281 & $\operatorname{chr} 15$ & 0.87 & 0.09 \\
\hline PRTG & 38 & 479 & 283 & $\operatorname{chr} 15$ & 0.08 & 0.08 \\
\hline CPLX3 & 12 & 97 & 214 & $\operatorname{chr} 15$ & 0.09 & 0.20 \\
\hline NUPR1 & 19 & 74 & 272 & $\operatorname{chr} 16$ & 0.09 & 0.11 \\
\hline MT1M & 108 & 477 & 1461 & $\operatorname{chr} 16$ & 0.17 & 0.04 \\
\hline MT1E & 240 & 988 & 3071 & $\operatorname{chr} 16$ & 0.01 & 0.02 \\
\hline MT1G & 254 & 466 & 3076 & $\operatorname{chr} 16$ & 0.05 & 0.11 \\
\hline MT1H & 162 & 186 & 1772 & $\operatorname{chr} 16$ & 0.11 & 0.07 \\
\hline ARSG & 11 & 133 & 136 & $\operatorname{chr} 17$ & 0.09 & 0.12 \\
\hline BAHCC1 & 9 & 101 & 43 & chr17 & 0.07 & 0.07 \\
\hline FLJ11710 & 51 & 549 & 464 & chr17 & 0.09 & 0.09 \\
\hline TAC4 & 8 & 49 & 196 & $\operatorname{chr} 17$ & 0.02 & 0.04 \\
\hline RAX & 11 & 1387 & 588 & $\operatorname{chr} 18$ & 0.08 & 0.09 \\
\hline RAX & 16 & 337 & 152 & $\operatorname{chr} 18$ & 0.10 & 0.13 \\
\hline APC2 & 61 & 564 & 907 & $\operatorname{chr} 19$ & 0.01 & 0.03 \\
\hline GPCPD1 & 117 & 1238 & 1002 & chr20 & 0.05 & 0.10 \\
\hline POTED & 59 & 884 & 847 & $\operatorname{chr} 21$ & 0.04 & 0.10 \\
\hline POTED & 58 & 619 & 634 & $\operatorname{chr} 21$ & 0.08 & 0.14 \\
\hline \multirow[t]{2}{*}{ PNCK } & 10 & 108 & 79 & $\operatorname{chrX}$ & 0.10 & 0.13 \\
\hline & 11 & 58 & 133 & $\operatorname{chrX}$ & 0.20 & 0.08 \\
\hline COPG2IT1 & 19 & 365 & 91 & & 0.05 & 0.20 \\
\hline
\end{tabular}



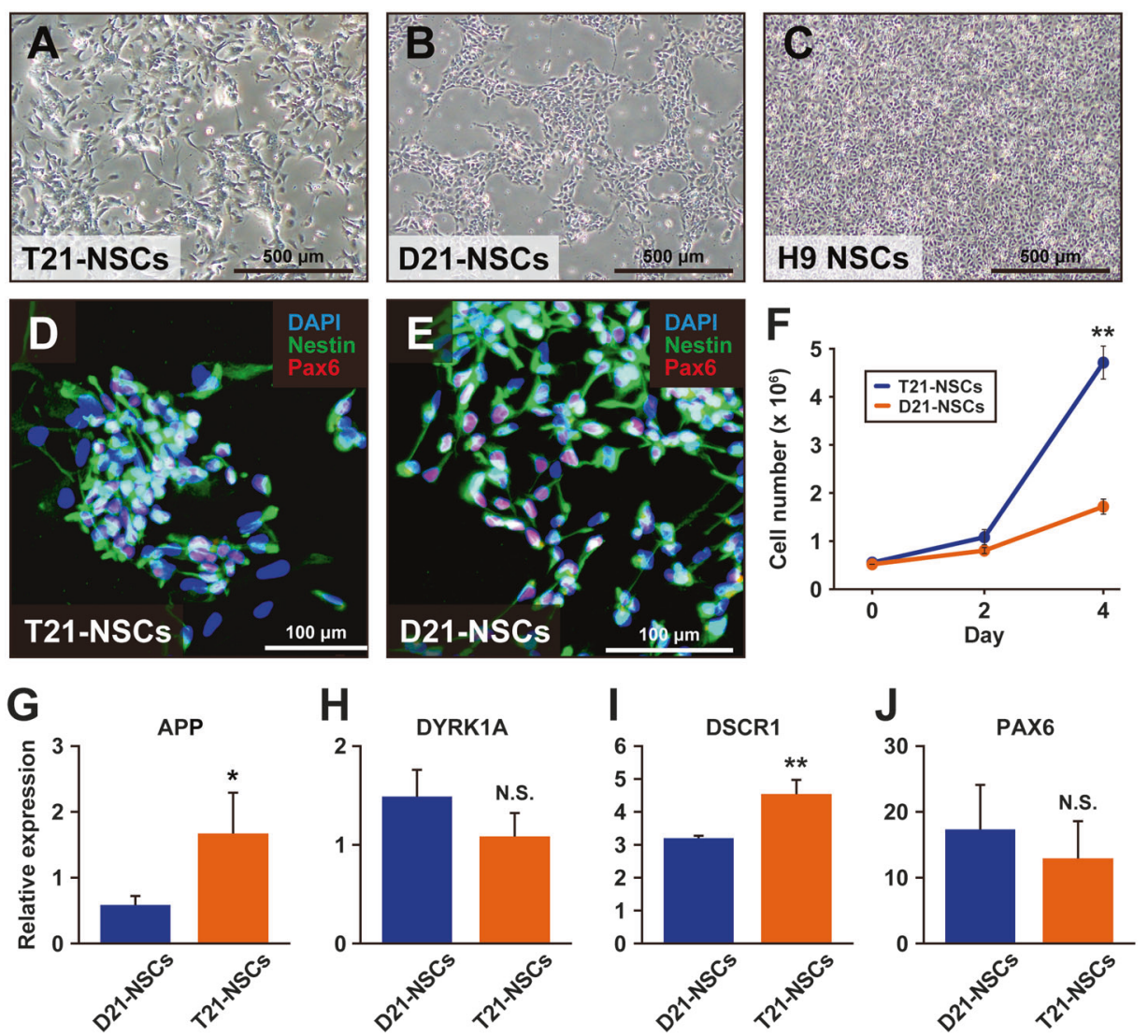

Fig. 3 Generation of neural stem cells from iPSCs. a Microscopic analysis of neural stem cells derived from T21-iPSC\#12 (T21-NSCs) at passage 4. b Microscopic analysis of neural stem cells derived from D21-iPSC\#2 (D21-NSCs) at passage 4. c Microscopic analysis of human neural stem cells (H9-NSC). d Immunocytochemistry of T21NSCs, using the antibodies to neural stem cell markers that are PAX6 (red) and Nestin (Green). Nuclei were counterstained with DAPI. e Immunocytochemistry of D21-NSCs, using the antibodies to neural stem cell markers that are PAX6 (red) and Nestin (Green). Nuclei were counterstained with DAPI. $\mathbf{f}$ The growth rate of T21-NSCs and D21-

\section{Induction of differentiation into NSCs}

We examined T21-iPSC\#12 and D21-iPSC\#2 for neural differentiation because Down's syndrome patients have intellectual disability. T21-iPSC\#12 and D21-iPSC\#2 efficiently differentiated into NSCs in morphology and neural marker expression (Fig. 3). NSCs derived from T21iPSC\#12 (T21-NSCs) and D21-iPSC\#2 (D21-NSCs) showed NSC-like morphology at passage 2. T21-NSCs and D21-NSCs were expressed NSC markers, i.e., PAX6 and Nestin. We measured the proliferation of T21-NSCs and D21-NSCs at passage 6. T21-NSCs grew more faster than D21-NSCs (Fig. 3f). qPCR analysis showed that the gene expression levels of APP and DSCR1 in T21-NSCs were higher than D21-NSCs (Fig. 3g, i). These results may suggest a possible link between clinical features of Down syndrome patients and T21-iPSC phenotypes.

NSCs at passage 6. Data shown are mean \pm SD of the cell number from three independent experiments. ${ }^{*} p<0.01$. g Real-time qPCR analysis of APP. Data shown are mean $\pm \mathrm{SD}$ of the expression from three independent experiments. ${ }^{*} p<0.05$. h Real-time qPCR analysis of DYRK1A. Data shown are mean \pm SD of the expression from three independent experiments. N.S., not significant. i Real-time qPCR analysis of DSCR1. Data shown are mean \pm SD of the expression from three independent experiments. $* * p<0.01$. j Real-time qPCR analysis of PAX6. Data shown are mean $\pm \mathrm{SD}$ of the expression from three independent experiments. N.S., not significant

\section{Keratinocytic differentiation of T21-iPSC and D21-iPSC}

We generated iPSC-derived keratinocytes, based on a previously described protocol [34]. Keratinocytes were derived from T21-iPSC\#12 (T21-KCs) and D21-iPSC\#2 (D21$\mathrm{KCs})$ showed keratinocyte-like morphology at passage 2 (Fig. 4a). T21-KCs showed a slow growth rate compared with D21-KCs (Fig. 4b). Immunostaining revealed the expression of KRT14 in both T21-KCs and D21-KCs (Fig. 4c). Moreover, we immortalized T21-KCs to secure a stable supply and established 3-dimensional cultures for skin models. T21-KCs continued to proliferate in vitro and were infected with lentivirus carrying the CDK4R24C, cyclin D1, and hTERT genes. The immortalized iPSCderived keratinocytes exhibited similar morphology to immortalized human keratinocytes (HDK1-K4DT) [40] 
A
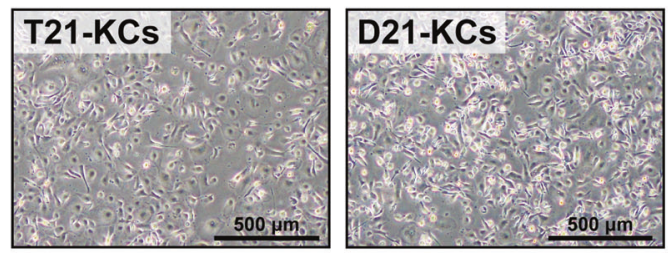

B

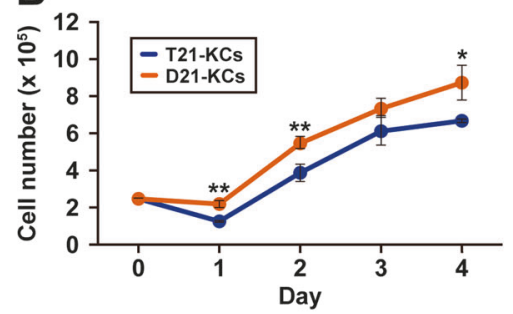

C

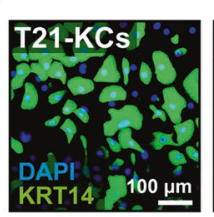

E
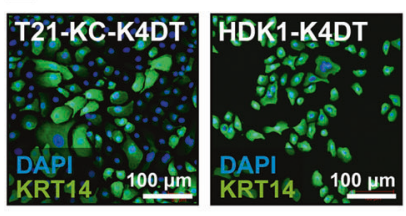

F T21-KC-K4DT
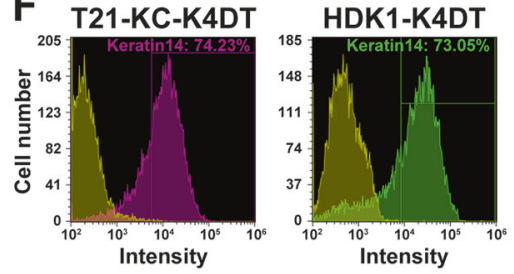

T21-KC-K4DT
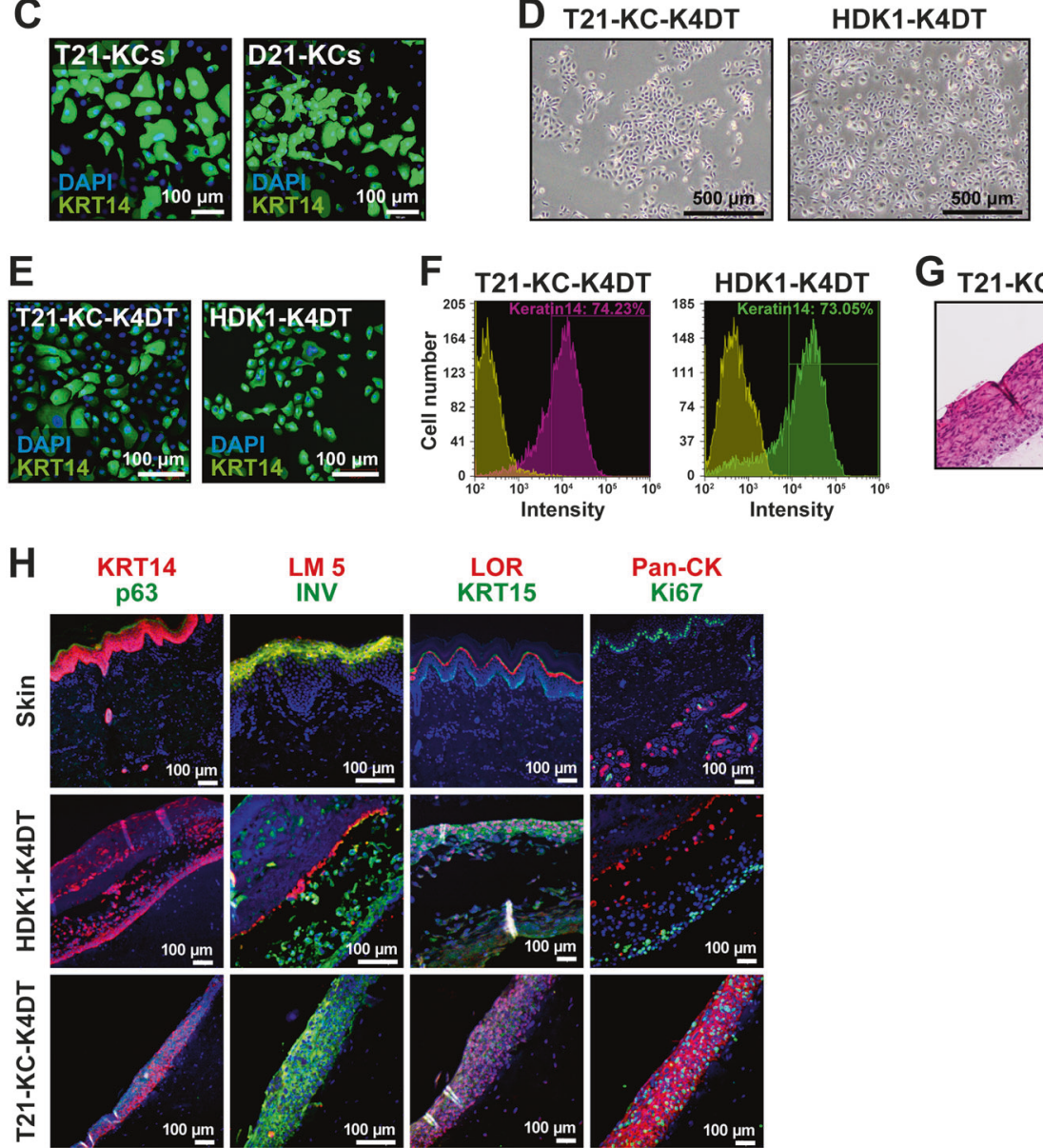

Fig. 4 Generation of keratinocytes from iPSCs. a Microscopic analysis of keratinocytes derived from T21-iPSC\#12 (T21-KCs) and D21-iPSC\#2 (D21-KCs) at passage 2. b Growth rate of T21-KCs and D21-KCs at passage 2. Data shown are mean $\pm \mathrm{SD}$ of the cell number from three independent experiments. c Immunocytochemistry of T21-KCs and D21KCs with the anti-KRT14 antibody. Nuclei were counterstained with DAPI. d Phase-contrast photomicrographs of T21-KC-K4DT and HDK1-K4DT cells. e Immunocytochemistry of T21-KC-K4DT and

(Fig. 4d). HDK1-K4DT was used for positive controls of immunocytochemistry or references. The infected cells were designated as T21-KC-K4DT. Immunocytochemistry and flow cytometric analysis clearly showed that T21-KCK4DT cells were positive for KRT14 (Fig. 4e, f). T21-KCK4DT formed stratified epithelium with keratinization after 3-dimensional cultivation (Fig. 4g). The T21-KC-K4DT epidermis expressed KRT14, p63, LM5, INV, LOR,
HDK1-K4DT cells with the anti-KRT14 antibody. Counterstained with DAPI. f Flow cytometric analysis of T21-KC-K4DT and HDK1-K4DT cells with the anti-KRT14 antibody. Isotype controls are shown in each panel. g Histology of T21-KC-K4DT and HDK1-K4DT epidermis in 3D culture. HE stain. h Immunohistochemistry of intact skin, HDK1-K4DT epidermis and T21-KC-K4DT epidermis (from top to bottom) with the antibodies to KRT14, p63, LM5, INV, LOR, KRT15, Pan-CK and Ki67. Counterstained with DAPI

KRT15, and Ki67 in a similar orientation to intact epidermis and HDK1-K4DT epidermis (Fig. 4h).

\section{Discussion}

In this study, we introduced a spontaneous trisomy rescue in Down syndrome-derived iPSCs. Chromosome 21 trisomy 
has been reported to be mostly due chromosomal nondisjunction during meiosis I in the maternal egg. In contrast, paternal chromosomal non-disjunction occurs during meiosis II (spermatidogenesis). Non-disjunction of chromosomes during meiosis I and meiosis II result in heterologous pair of chromosomes and duplicated homologous pair of chromosomes, respectively. Presence of three different STR patterns in T21-iPSC\#12 generated in this study suggests chromosomal non-disjunction during meiosis I. Possibility of other cell contamination can also be excluded by the same STR pattern between the trisomic and disomic cells. Furthermore, mosaicism of trisomic and disomic cells from the donor can also be excluded because the amniotic fluid-derived parental cells exhibit chromosome 21 trisomy exclusively and disomic cells have been reproducibly obtained from $100 \%$ trisomy cells.

Proliferation rates of trisomic cells are considered to be tissue-dependent; the proliferation rate of trisomic cells is low in mouse embryonic fibroblasts and in fibroblasts from Down syndrome fetuses, but high in hematopoietic cells [41-44]. Trisomy 21 cells are highly responsive to a variety of external stimuli acting through cell-surface receptors, such as genes encoding the interferon- $\alpha / \beta$ receptor and IFN- $\gamma$ receptor on chromosome 21 [44]. The differential growth rates of iPSCderived keratinocytes and NSCs in this study were consistent with this tissue-dependent Trisomy 21 cell growth.

Trisomy rescue arises from mitotic or meiotic nondisjunction, and the nondisjunction of chromosome 21 occurs more often in trisomic cells than in normal cells $[45,46]$. Likewise, trisomic rescue during iPSC cultivation in this study can possibly be attributed to chromosomal nondisjunction. Interestingly, the proportion of trisomic cells in blood cells is lower than that in skin fibroblasts cultured from the same individual, and the frequency of trisomic rescue is tissue-dependent [44]. Elucidating the conditions in which aneuploid iPSCs produce revertant cells may facilitate the development of treatments for various chromosomal abnormalities.

Differences between trisomic and disomic cells are of interest because the genetic background of these cells is the same. The benefit of Down syndrome iPSC availability is pluripotency and immortality. Additionally, Down syndrome iPSCs can efficiently differentiate into neural and hematopoietic cells that are associated with mental retardation and leukemogenesis, respectively. Expression levels of Down syndrome-related genes such as SOD1, DYRK1A, ETS2, APP, and DSCR1 in chromosome 21 are comparable with the gene number, i.e., three 21 chromosomes. Cells rescued from trisomy serve as a good control for Down syndrome cells due to the same/similar genetic background. These differentiated cells can contribute to drug development for Down syndrome in two ways: (1) Correction of gene expression levels, i.e., ets2, dyrk1a, dscr1, and app; (2)
Increased frequency of trisomic rescue. Drug re-profiling is most practical to fetus with Down syndrome as well as Down syndrome patients. Predicted usage may include treatment of mental retardation and prevention of leukemogenesis. Low molecular weight molecules have been clinically investigated in Down syndrome patients [9]. However, no studies have yet reported correction of mental retardation. Neurogenesis continues in the ventricular and subventricular zones of the cerebral cortex in the third trimester of pregnancy [47], and therapeutic intervention in fetus could therefore be possible. Drug may restore neurogenesis, enhance cortical growth, and improve the neurodevelopmental outcome of Down syndrome.

Acknowledgements The authors would like to thank Kenji Miyado for the fruitful discussion.

\section{Compliance with ethical standards}

Conflict of interest The authors declare that they have no conflict of interest.

Ethical statement The protocol for using human cells in this study was approved by the Institution Review Board of the National Research Institute for Child Health and Development of Japan and was fully compliant with the Ethical Guidelines for Clinical Studies (Ministry of Health, Labor, and Welfare).

Publisher's note: Springer Nature remains neutral with regard to jurisdictional claims in published maps and institutional affiliations.

Open Access This article is licensed under a Creative Commons Attribution 4.0 International License, which permits use, sharing, adaptation, distribution and reproduction in any medium or format, as long as you give appropriate credit to the original author(s) and the source, provide a link to the Creative Commons license, and indicate if changes were made. The images or other third party material in this article are included in the article's Creative Commons license, unless indicated otherwise in a credit line to the material. If material is not included in the article's Creative Commons license and your intended use is not permitted by statutory regulation or exceeds the permitted use, you will need to obtain permission directly from the copyright holder. To view a copy of this license, visit http://creativecommons. org/licenses/by/4.0/.

\section{References}

1. Samura O, Sekizawa A, Suzumori N, Sasaki A, Wada S, Hamanoue $\mathrm{H}$, et al. Current status of non-invasive prenatal testing in Japan. J Obstet Gynaecol Res. 2017;43:1245-55.

2. Sago H, Sekizawa A. Nationwide demonstration project of nextgeneration sequencing of cell-free DNA in maternal plasma in Japan: 1-year experience. Prenat Diagn. 2015;35:331-6.

3. Yang A, Currier D, Poitras JL, Reeves RH. Increased Skin Tumor Incidence and Keratinocyte Hyper-Proliferation in a Mouse Model of Down Syndrome. PLoS ONE. 2016;11:e0146570.

4. Hattori M, Fujiyama A, Taylor TD, Watanabe H, Yada T, Park HS, et al. The DNA sequence of human chromosome 21. Nature. 2000;405:311-9. 
5. Shukkur EA, Shimohata A, Akagi T, Yu W, Yamaguchi M, Murayama M, et al. Mitochondrial dysfunction and tau hyperphosphorylation in Ts1Cje, a mouse model for Down syndrome. Hum Mol Genet. 2006;15:2752-62.

6. Kurabayashi N, Sanada K. Increased dosage of DYRK1A and DSCR1 delays neuronal differentiation in neocortical progenitor cells. Genes Dev. 2013;27:2708-21.

7. Nakano-Kobayashi A, Awaya T, Kii I, Sumida Y, Okuno Y, Yoshida S, et al. Prenatal neurogenesis induction therapy normalizes brain structure and function in Down syndrome mice. Proc Natl Acad Sci USA. 2017;114:10268-73.

8. McElyea SD, Starbuck JM, Tumbleson-Brink DM, Harrington E, Blazek JD, Ghoneima A, et al. Influence of prenatal EGCG treatment and Dyrk1a dosage reduction on craniofacial features associated with Down syndrome. Hum Mol Genet. 2016;25:4856-69.

9. de la Torre R, de Sola S, Hernandez G, Farré M, Pujol J, Rodriguez J, et al. Safety and efficacy of cognitive training plus epigallocatechin-3-gallate in young adults with Down's syndrome (TESDAD): a double-blind, randomised, placebo-controlled, phase 2 trial. Lancet Neurol. 2016;15:801-10.

10. Incerti M, Horowitz K, Roberson R, Abebe D, Toso L, Caballero $\mathrm{M}$, et al. Prenatal treatment prevents learning deficit in Down syndrome model. PLoS ONE. 2012;7:e50724.

11. Reeves RH, Irving NG, Moran TH, Wohn A, Kitt C, Sisodia SS, et al. A mouse model for Down syndrome exhibits learning and behaviour deficits. Nat Genet. 1995;11:177-84.

12. Sago H, Carlson EJ, Smith DJ, Kilbridge J, Rubin EM, Mobley WC, et al. Ts1Cje, a partial trisomy 16 mouse model for Down syndrome, exhibits learning and behavioral abnormalities. Proc Natl Acad Sci USA. 1998;95:6256-61.

13. Sago H, Carlson EJ, Smith DJ, Rubin EM, Crnic LS, Huang TT, et al. Genetic dissection of region associated with behavioral abnormalities in mouse models for Down syndrome. Pediatr Res. 2000;48:606-13.

14. Amano K, Sago H, Uchikawa C, Suzuki T, Kotliarova SE, Nukina $\mathrm{N}$, et al. Dosage-dependent over-expression of genes in the trisomic region of Ts1Cje mouse model for Down syndrome. Hum Mol Genet. 2004;13:1333-40.

15. Gardiner K, Fortna A, Bechtel L, Davisson MT. Mouse models of Down syndrome: how useful can they be? Comparison of the gene content of human chromosome 21 with orthologous mouse genomic regions. Gene. 2003;318:137-47.

16. Holtzman DM, Santucci D, Kilbridge J, Chua-Couzens J, Fontana DJ, Daniels SE, et al. Developmental abnormalities and agerelated neurodegeneration in a mouse model of Down syndrome. Proc Natl Acad Sci USA. 1996;93:13333-8.

17. Richtsmeier JT, Zumwalt A, Carlson EJ, Epstein CJ, Reeves RH. Craniofacial phenotypes in segmentally trisomic mouse models for Down syndrome. Am J Med Genet. 2002;107:317-24.

18. Guidi S, Stagni F, Bianchi P, Ciani E, Giacomini A, De Franceschi M, et al. Prenatal pharmacotherapy rescues brain development in a Down's syndrome mouse model. Brain. 2014;137 (Pt 2):380-401.

19. Powers BE, Kelley CM, Velazquez R, Ash JA, Strawderman MS, Alldred MJ, et al. Maternal choline supplementation in a mouse model of Down syndrome: Effects on attention and nucleus basalis/substantia innominata neuron morphology in adult offspring. Neuroscience. 2017;340:501-14.

20. Rachubinski AL, Maclean KN, Evans JR, Bjugstad KB. Modulating cognitive deficits and tau accumulation in a mouse model of aging Down syndrome through neonatal implantation of neural progenitor cells. Exp Gerontol. 2012;47:723-33.

21. Hashimoto A, Naito AT, Lee JK, Kitazume-Taneike R, Ito M, Yamaguchi T, et al. Generation of induced pluripotent stem cells from patients with duchenne muscular dystrophy and their induction to cardiomyocytes. Int Heart J. 2016;57:112-7.
22. Ninomiya E, Hattori T, Toyoda M, Umezawa A, Hamazaki T, Shintaku H. Glucocorticoids promote neural progenitor cell proliferation derived from human induced pluripotent stem cells. + . 2014;3:527.

23. Masuda S, Matsuura K, Shimizu T. Preparation of iPS cellderived $\mathrm{CD} 31+$ endothelial cells using three-dimensional suspension culture. Regen Ther. 2018;9:1-9.

24. Kojima J, Fukuda A, Taira H, Kawasaki T, Ito H, Kuji N, et al. Efficient production of trophoblast lineage cells from human induced pluripotent stem cells. Lab Invest. 2017;97:1188-200.

25. Ikemoto Y, Takayama Y, Fujii K, Masuda M, Kato C, Hatsuse H, et al. Somatic mosaicism containing double mutations in PTCH1 revealed by generation of induced pluripotent stem cells from nevoid basal cell carcinoma syndrome. J Med Genet. 2017; 54:579-84.

26. Lu S, Kanekura K, Hara T, Mahadevan J, Spears LD, Oslowski $\mathrm{CM}$, et al. A calcium-dependent protease as a potential therapeutic target for Wolfram syndrome. Proc Natl Acad Sci USA. 2014;111: E5292-301.

27. Santostefano KE, Hamazaki T, Biel NM, Jin S, Umezawa A, Terada N. A practical guide to induced pluripotent stem cell research using patient samples. Lab Invest. 2015;95:4-13.

28. Teshigawara R, Cho J, Kameda M, Tada T. Mechanism of human somatic reprogramming to iPS cell. Lab Invest. 2017;97:1152-7.

29. Hibaoui Y, Grad I, Letourneau A, Sailani MR, Dahoun S, Santoni FA, et al. Modelling and rescuing neurodevelopmental defect of Down syndrome using induced pluripotent stem cells from monozygotic twins discordant for trisomy 21. EMBO Mol Med. 2014;6:259-77.

30. Li LB, Chang KH, Wang PR, Hirata RK, Papayannopoulou T, Russell DW. Trisomy correction in Down syndrome induced pluripotent stem cells. Cell Stem Cell. 2012;11:615-9.

31. Jiang J, Jing Y, Cost GJ, Chiang JC, Kolpa HJ, Cotton AM, et al. Translating dosage compensation to trisomy 21. Nature. 2013; 500:296-300.

32. Bershteyn M, Hayashi Y, Desachy G, Hsiao EC, Sami S, Tsang $\mathrm{KM}$, et al. Cell-autonomous correction of ring chromosomes in human induced pluripotent stem cells. Nature. 2014;507:99-103.

33. Hirota T, Ohta H, Powell BE, Mahadevaiah SK, Ojarikre OA, Saitou M, et al. Fertile offspring from sterile sex chromosome trisomic mice. Science. 2017;357:932-5.

34. Kajiwara K, Tanemoto T, Wada S, Karibe J, Ihara N, Ikemoto Y, et al. Fetal therapy model of myelomeningocele with threedimensional skin using amniotic fluid cell-derived induced pluripotent stem cells. Stem Cell Rep. 2017;8:1701-13.

35. Okamura K, Sakaguchi H, Sakamoto-Abutani R, Nakanishi M, Nishimura K, Yamazaki-Inoue M, et al. Distinctive features of single nucleotide alterations in induced pluripotent stem cells with different types of DNA repair deficiency disorders. Sci Rep. 2016;6:26342.

36. Okamura K, Toyoda M, Hata K, Nakabayashi K, Umezawa A. Whole-exome sequencing of fibroblast and its iPS cell lines derived from a patient diagnosed with xeroderma pigmentosum. Genom Data. 2015;6:4-6.

37. Fukawatase Y, Toyoda M, Okamura K, Nakamura K, Nakabayashi K, Takada S, et al. Ataxia telangiectasia derived iPS cells show preserved x-ray sensitivity and decreased chromosomal instability. Sci Rep. 2014;4:5421.

38. Shiomi K, Kiyono T, Okamura K, Uezumi M, Goto Y, Yasumoto $\mathrm{S}$, et al. CDK4 and cyclin D1 allow human myogenic cells to recapture growth property without compromising differentiation potential. Gene Ther. 2011;18:857-66.

39. Miyoshi H. Gene delivery to hematopoietic stem cells using lentiviral vectors. Methods Mol Biol. 2004;246:429-38.

40. Egawa N, Nakahara T, Ohno S, Narisawa-Saito M, Yugawa T, Fujita M, et al. The E1 protein of human papillomavirus type 16 is 
dispensable for maintenance replication of the viral genome. $\mathrm{J}$ Virol. 2012;86:3276-83.

41. Williams BR, Prabhu VR, Hunter KE, Glazier CM, Whittaker CA, Housman DE, et al. Aneuploidy affects proliferation and spontaneous immortalization in mammalian cells. Science. 2008;322:703-9.

42. Gimeno A, García-Giménez JL, Audí L, Toran N, Andaluz P, Dasí $\mathrm{F}$, et al. Decreased cell proliferation and higher oxidative stress in fibroblasts from Down Syndrome fetuses. Preliminary study. Biochim Biophys Acta - Mol Basis Dis. 2014;1842:116-25.

43. Murray A, Letourneau A, Canzonetta C, Stathaki E, Gimelli S, Sloan-Bena $\mathrm{F}$, et al. Brief Report: isogenic induced pluripotent stem cell lines from an adult with mosaic Down syndrome model accelerated neuronal ageing and neurodegeneration. Stem Cells. 2015;33:2077-84.

44. Epstein CJ. Down syndrome (Trisomy 21). In: Scriver CR, Beaudet AL, Sly WS, et al., editors. The metabolic \& molecular bases of inherited disease. 8th edn. New York, NY: McGraw-Hill, 2001. pp. 1223-56.

45. Conlin LK, Thiel BD, Bonnemann CG, Medne L, Ernst LM, Zackai EH, et al. Mechanisms of mosaicism, chimerism and uniparental disomy identified by single nucleotide polymorphism array analysis. Hum Mol Genet. 2010;19: 1263-75.

46. Shi Q, Adler ID, Zhang J, Zhang X, Shan X, Martin R. Incidence of mosaic cell lines in vivo and malsegregation of chromosome 21 in lymphocytes in vitro of trisomy 21 patients: detection by fluorescence in situ hybridization on binucleated lymphocytes. Hum Genet. 2000;106:29-35.

47. Malik S, Vinukonda G, Vose LR, Diamond D, Bhimavarapu BB, $\mathrm{Hu} \mathrm{F}$, et al. Neurogenesis continues in the third trimester of pregnancy and is suppressed by premature birth. J Neurosci. 2013;33:411-23. 